\title{
EDITORIAL
}

\section{Nordic health system performance comparison}

The editorial in Issue 2 of the Nordic Journal of Health Economics (Häkkinen and Iversen, 2012) claimed that bold reform proposals in health care are often initiated with scant knowledge of their effects. Accordingly, evidence based health policy requires more research on the effects of the organization of care, including comparative studies across countries. In Nordic countries, health care sectors demonstrate the same basic structure, which consists of a tax-based public health insurance system that covers the entire population, the dominance of public ownership and operation of hospitals, available registry data representing entire populations, and only a small proportion of health services funded by private health insurance. Despite the similarity of the sectors, comparative studies in Nordic countries have only to a small extent used available registry data. At the same time, variation in the organization of care and financing afford several exciting opportunities for examining their potential impacts.

In response, the editors of the Nordic Journal of Health Economics decided to devote a special issue to economics papers comparing the performance of the health sectors in Nordic countries. At the general level, performance measures evaluate the extent to which a health care system meets key objectives, including efficiency, quality, outcomes, accessibility, and equity. The international comparison of performance can take several perspectives that variously address entire systems, certain diseases, or sub-sector of care (e.g., hospitals, nursing homes, primary care, and medication). In effect, international comparison can be used for benchmarking (learning from the best practices) and to investigate reasons for variation in performance.

This special issue contains five papers. One paper addresses social inequality in health, whereas the four others examine the effects of the organization of care on cost and quality with Nordic registry data. All papers adopt a cross-country comparative perspective.

In the first paper, Christiansen, Lauridsen, Kifmann, Lyttkens, Ólafsdóttir, and Valtonen examine the extent to which populations in Nordic countries have achieved good health and a high degree of socioeconomic equality in health. They analyzed socioeconomic inequity by using both traditional (i.e., comparison of percentages reporting good or very good health across lower- and upper-income groups) and more sophisticated measures (i.e., concentration indices) developed by health economists. They show that, in general, Nordic countries have achieved good health for their populations as well as a high degree of socioeconomic equality in health. Income-related inequalities in health in the Nordic countries were shown to be similar to or less than those in less egalitarian countries such as Germany and the United Kingdom.

Kittelsen, Anthun, Häkkinen, Kruse, and Rehnberg examine whether including quality-related variables, including emergency readmissions and mortality within 30 days, in production models change estimates of scale elasticity. They hypothesized that the elasticity of scale would increase when models include those variables, which they tested against the null hypothesis that no change in scale elasticity would occur. Because their analysis did not support the existence of volume-based effects on key quality indicators strong enough to increase scale elasticity at the hospital level, they conclude that further research on the mechanisms of returns to scale among different patient groups and in hospital-level measures of performance is necessary. 
Moger, Häkkinen, and Hagen report that mortality rates in Finland and Norway are similar for major diseases, albeit with acute coronary syndrome (ACS) as an important exception. For ACS, mortality is significantly greater in Finland than in Norway. The authors examined whether a more decentralized structure of emergency treatment, including invasive procedures, in Finland explained differences in mortality between the countries. After adjusting for individual and regional variables, they find that mortality is $2-4 \%$ lower in Norway in most categories of hospital system variables included in their analyses. Hence, they could not explain the differences in mortality in terms of differences in the organization of care.

Next, Iversen and Häkkinen extended the Finland-Norway comparison on heart attack patients by analyzing variation in treatment costs between the countries and by introducing novel explanatory variables. They found that the distance from a patient's home to the hospital increased hospital costs at a declining scale and that one-year hospital costs were greater for low-income patients. Higher one-year hospital costs in Norway were accompanied by a lower mortality rate. Whereas introducing new explanatory variables did not explain the greater costs in Finland than in Norway for the first hospital episode, for one-year costs the additional variables explained the greater costs in Norway than in Finland.

In the last paper, Häkkinen, Hagen, and Moger compare performance indicators of hip fracture patients from the Helsinki area (i.e., a more vertically integrated system) and Oslo (i.e., a system that splits responsibility for patients between the municipality and stateowned hospitals). They also studied the effects of the Coordination Reform implemented in Norway by difference-in-differences methodology to find that shorter hospital stays in Norway after the reform were more than compensated by longer stays in long-term care institutions. In Oslo after the reform, more patients with hip fracture were institutionalized and fewer were discharged to their homes, whereas opposite trends occurred in Helsinki.

Included in this issue is also a Commentary written by Professor Kjeld Møller Pedersen, who is a pioneer in health economics research in the Nordic countries. In the Commentary, he draws on his unique combination of knowledge of economics, political science, medicine and policy-making in setting the articles in a critical perspective. The Commentary nicely summarizes and comments each of research articles included in the issue. As concluding observations he highlights the difficulty in making comparisons and the importance of institutional detail, and raises concerns about lacking institutional details in combination with a general tendency of too little theory behind hypotheses. These are very relevant points that should be kept in mind in future studies.

The articles in this special issue underscore new, detailed perspectives on measuring the performance of health care provision in Nordic countries. Data from national health information systems vary among countries in terms of coverage, coding and terminology, quality, share-ability, and the potential for linkage (OECD, 2015). Such variation represents a main challenge of every international comparison of performance, although in Nordic countries, registries are developed well and can be linked by using personal identification numbers. Another problem in both international and Nordic comparative studies has been the difficulty of pooling data from different countries. Nevertheless, pooling was possible in three studies comparing Norway and Finland presented in this issue. Current technology (e.g., services for sensitive data at the University of Oslo) facilitated pooled analysis in a secure data portal and means to ensure the privacy of data. ${ }^{1}$

\footnotetext{
${ }^{1}$ See https://www.uio.no/english/services/it/research/sensitive-data/
} 
Three of the papers indicate that analyzing the performance of health care providers in Nordic countries can be developed by harmonizing cost information and the content of registries describing the use of services, as well as by gathering routine information on measures of daily activity among the elderly. More generally, the papers indicate the potential to create a Nordic research infrastructure that can allow researchers to compare the efficiency and performance of Nordic healthcare systems, analyze reasons for observed differences, and evaluate the effects of recent reforms on efficiency and equity. Above all, the quality of comparisons of performance in Nordic countries can improve considerably if individual-level data can be pooled in a secure data portal and in secure facilities.

Unto Häkkinen, Tor Iversen and Åsa Ljungvall

\section{References}

Häkkinen, U. and Iversen, T. (2012). Editorial. Nordic Journal of Health Economics, Vol. 1, No. 2 , pp. 5-7.

OECD (2015). Health Data Governance: Privacy, Monitoring and Research, OECD Health Policy Studies. Paris: OECD Publishing. 